\title{
CHLORIN E6 COMBINED WITH ALBUMIN NANOPARTICLES AS A POTENTIAL COMPOSITE PHOTOSENSITIZER FOR PHOTODYNAMIC THERAPY OF TUMORS
}

\author{
I.O. Shton, V.V. Sarnatskaya, I.V. Prokopenko, N.F. Gamaleia* \\ R.E. Kavetsky Institute of Experimental Pathology, Oncology and Radiobiology, NAS of Ukraine, Kyiv 03022, Ukraine
}

Aim: To synthesize and to study for photodynamic activity a composite photosensitizer consisting of chlorin e6 and human serum albumin nanoparticles (HSA NPs). Materials and Methods: Starting from sorption-purified HSA, the albumin nanoparticles with a different degree of lysine residues cross-linking $(10 ; 20 ; 40$, and $100 \%)$ were obtained by the coacervation method. The HSA NPs were used for synthesis of nanocomposites with chlorin e6 and fluorescein isothiocyanate (FITC)-labled preparations. Malignant lymphocytes of the MT-4 (human T-cell leukemia) line and normal lymphocytes of healthy donors served as cell targets. For photodynamic treatment, a semiconductor laser was exploited as a light source, and cell viability was assessed by MTT or trypan blue dye exclusion tests. For cell imaging and HSA NPs visualization, the fluorescence microscopy and transmission electron microscopy were applied, respectively. $\mathrm{C} 57 \mathrm{Bl} / 6$ mice were used in animal experiments. Results: The absorption and fluorescence spectra of chlorin e6-HSA NPs composites were characterized, and by the electron microscopy investigation the size of NPs (nanospheres) was estimated: 100-120 nm. FITC-labled albumin preparations allowed to establish that HSA NPs have much higher exposition and concentration dependent affinity to malignant cell surface than initial HSA. In experiments with MT-4 cells on PDT activity of chlorin e6-HSA NPs, the nanocomposite effectiveness elevated along with increasing percentage of cross-linked aminoacid residues, and for the nanocomposite with $100 \%$ of albumin cross-linking it exceeded the activity of free chlorin e6. In contrast to malignant cells, the complexation of chlorin e6 with HSA NPs decreased its photodynamic effect on normal human lymphocytes. Intravenous introduction of the chlorin e6-HSA NPs composite to mice showed prolonged circulation of the nanocomposite in blood in comparison with free PS. Conclusion: Promising results obtained with chlorin e6-HSA NPs composites warrant conduction of full-fledged PDT studies in vivo using the nanocomposites as photosensitizers.

Key Words: human serum albumin, nanoparticles, photodynamic therapy, chlorin e6, cell line MT-4, C57Bl/6 mice.

Photodynamic therapy (PDT) of tumors is a modern low-traumatic method for oncological patients' treatment that is winning ever-growing recognition due to the absence of serious complications, comparative selectivity of antitumor action and moderate cost. Active researches are conducted to raise the method selectivity and to expand the sphere of its clinical applications. A promising approach to the problem of improving conventional PDT potency consists in designing efficient carrier systems for a photosensitizing drug used [1, 2]. One way to attain that is to employ as photosensitizer (PS) carriers certain non-toxic biocompatible polymers (e.g., polyethylene glycol, polyvinylpyrrolidone) which are able to extend the PS circulation time and to increase its accumulation in tumor tissues due to enhanced permeation and retention (EPR) phenomenon [3, 4]. Another possibility is based on application of composite PSs comprising molecules which have high and/or selective affinity to tumor tissues (transferrin, folic acid, specific antibodies) and provide for targeted PS transportation to the tumor [5]. In this context, it seems tempting to test as PS carriers the substances which are potentially capable of both mechanisms mentioned. A serum albumin may be considered one suitable candidate for the role. Being a dominant protein of human blood plasma, it is biodegradable, non-antigenic and

Submitted: December 01, 2015.

*Correspondence: E-mail: gamaleia@onconet.kiev.ua

Abbreviations used: EPR - enhanced permeation and retention;

FITC - fluorescein isothiocyanate; HSA - human serum albumin; NPs nanoparticles; PDT - photodynamic therapy; PS - photosensitizer. functionates in particular as a major natural porphyrine carrier in the body [6]. Most important, many tumor cells likely have on their surface a larger number of serum albumin receptors, in comparison with normal cells [7]. However, in its native form serum albumin does not fit to serve as a drug transporter and has to be cross-linked or stabilized using various known methods. Numerous experiments on delivery of diverse drugs with the help of modified serum albumin were conducted starting from 1970s [8].

PDT studies in which cross-linked human serum albumin was used as a vehicle for PS transportation were presented in a series of publications by B. Roeder and collaborators [9-12]. The studied PSs included pheophorbide and Foscan.

In this work we set the task to prepare and to examine for the photodynamic activity a nanocomposite PS that was not characterized earlier: the cross-linked human serum albumin (HSA) bearing Photolon a PS approved for PDT applications in Ukraine.

\section{MATERIALS AND METHODS}

Preparation of albumin nanoparticles. For our experiments we used protein nanospheres obtained by coacervation method [13] from HSA deliganded with hemosorbents. Albumin nanoparticles (HSA NPs) were treated with different amounts of cross-linking agent glutaraldehyde to obtain preparations with various degrees of cross-linked lysine residues (20; 40, and $100 \%$ ).

HSA NP conjugation with fluorescein isothiocyanate. HSA and HSA NPs were dissolved, dialyzed 
against bicarbonate buffer and lyophilized. Lyophilisates were dissolved in bicarbonate buffer to the concentration of $8 \mathrm{mg} / \mathrm{ml}$. Solutions were dialyzed overnight. Fluorescein isothiocyanate (FITC) in dimethylsulfoxide was added to HSA or HSA NP solutions and stirred for $60 \mathrm{~min}$ at $37^{\circ} \mathrm{C}$. To remove unbound dye, solutions were twice dialyzed overnight. All manipulations were performed in a dark room. The efficiency of conjugation was analyzed using fluorescence spectroscopy.

Nanocomposite PS preparation. Photolon (molecular complex of chlorin e6 sodium salt and polyvinylpirrolidone 1:1) was purchased from "Belmedpreparaty" (Belarus). It was dissolved in Hanks solution (Sigma-Aldrich, USA) and mixed with HSA NPs. Because chlorin e6 is unstable in water solutions, PS and its nanocomposite solutions were prepared immediately before each experiment.

Cell line and cell culture. The MT-4 (human T-cell leukemia) cell line was obtained from the culture bank of R.E. Kavetsky Institute for Experimental Pathology, Oncology and Radiobiology National Academy of Sciences of Ukraine. Cells in RPMI-1640 medium (Biowest, France) containing 10\% fetal bovine serum (Biowest, France) were maintained in humidified air at $37^{\circ} \mathrm{C}$ with $5 \%$ carbon dioxide. Normal lymphocytes were isolated from peripheral blood of healthy donors by routine gradient-density method.

Cell survival assay. For PDT tests, cell suspensions $\left(0.5 \cdot 10^{6}\right.$ per $\left.\mathrm{ml}\right)$ in Hanks balanced salt solution were prepared from MT-4 leukemic cells in a log phase of growth, or from normal limphocytes. After $1.5 \mathrm{~h}$ of incubation $\left(37^{\circ} \mathrm{C}\right)$ in Hanks solution with chlorin e 6 alone or with HSA NP-chlorin e6 nanocomposite (employing the same PS concentrations as for chlorin e6 alone), the cells were washed twice with a 10-fold volume of fresh Hanks solution and exposed to the red laser light (dose of $1 \mathrm{~J} / \mathrm{cm}^{2}$, fluence rate of $1.1 \mathrm{~mW} / \mathrm{cm}^{2}$ ), with control "dark" samples treated without irradiation. Then cells were transferred to culture medium. Cell viability was assessed using MTT test or trypan blue dye exclusion test after 18 hours of postincubation. 3-(4.5-dimethylthiazol-2-yl)-2.5-diphenyltetrazolium bromide for MTT test was obtained from Sigma-Aldrich (USA).

Photoirradiation procedure. For irradiation of cells, preincubated with photosensitizing agents, the semiconductor laser (Fotonica Plus, Ukraine) with emission wavelength of $658 \mathrm{~nm}$ was used. Light doses were determined using an Ophir Nova II laser Power/ Energy Meter (Ophir Optronics, Israel).

Cells fluorescence microscopy. The MT-4 cells were seeded in incubation medium (RPMI 1640 with $10 \%$ fetal bovine serum) at $1.5 \cdot 10^{5} \mathrm{cells} /$ well in a 96 -well plates. HSA-NPS-FITC or HSA-FITC was added to cells at concentrations of 30 and $300 \mu \mathrm{g} / \mathrm{ml}$ by albumin and incubated in humidified atmosphere at $37^{\circ} \mathrm{C}$. Cells were then washed three times with Hanks solution, and fluorescence of cells was determined by fluorescence microscopy (MC $300 \mathrm{FX}$ (Infinitive, Austria)) after 0.5; $1.5 ; 4$, and $24 \mathrm{~h}$ of cell incubation with FITC conjugates.
Determination of chlorin e6 and its nanocomposite clearance from the blood. The kinetics of PS and its composite with HSA-NPs elimination from the bloodstream of C57BL/ 6 mice (age $-2-2.5$ months, weight $-19-20 \mathrm{~g}$ ) was determined $15 \mathrm{~min}, 1 \mathrm{~h}, 3 \mathrm{~h}$ and $24 \mathrm{~h}$ after photosensitizing agents administration in the animal tail vein. The concentration of chlorin e6 introduced with the PS and its nanocomposite was the same $(2.5 \mathrm{mg} / \mathrm{kg})$. Chlorin e6 concentration in blood plasma was determined by fluorescence at a wavelength of 660-670 nm using fluorospectrometer NanoDrop ND3300 (NanoDrop, USA). The use of experimental animals have been performed in accordance with the international ethical standards.

Statistical analysis. To examine the differences between groups One-way ANOVA test was performed using OriginLab program. Differences between values with $p<0.05$ were considered to be significant. The values were expressed as means \pm standard deviation (SD). Experimental data were obtained in triplicates.

\section{RESULTS AND DISCUSSION}

Physico-chemical characteristics of HSA NPs and their composites with chlorin e6. In this study, HSA (fraction V, obtained from Sigma, USA) was used after its thorough deligandization by sorption as it was described earlier [14]. Such purified HSA has many vacant binding sites, demonstrating higher values of complexation enthalpy with marker substances (sodium octanuate, salicylic acid, phenol red, stearic acid) in flow isothermal microcalorimetry tests and increased binding of warfarin and diazepam - markers of the first and second drug binding sites, respectively [15].

HSA NPs were synthesized from the purified albumin using glutaraldehyde as a cross-linking agent via the coacervation method [16]. The NP fraction yield made $60-70 \%$ of total protein. The degree of lysine residues cross-linking (20; 40, and $100 \%)$ was determined by the amount of glutaraldehyde used, with $100 \%$ standing for cross-linking of all 49 lysine residues in HSA molecules. The electron microscopy investigation showed that HSA NPs present a narrowdispersed population of nanoparticles with a smooth surface and diameter of 100-120 nm (Fig. 1).

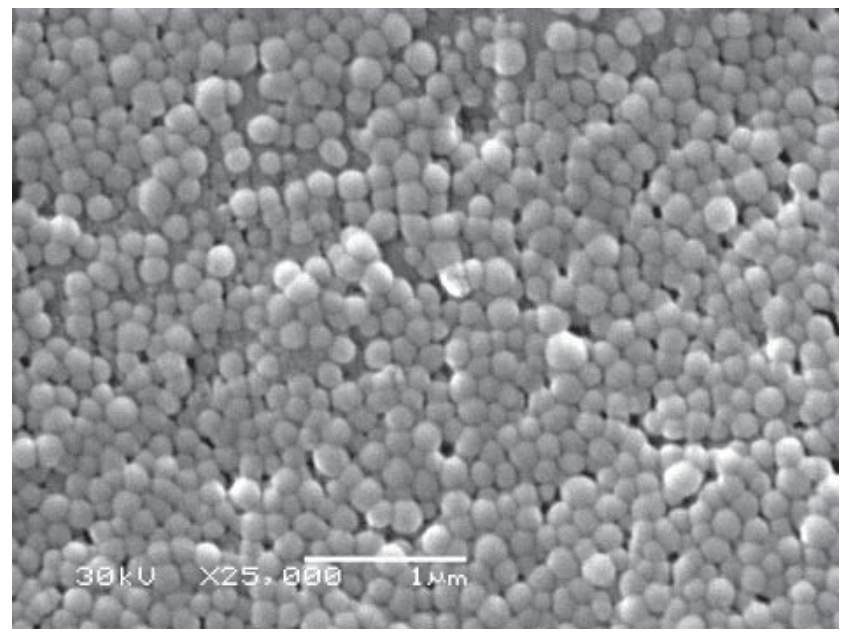

Fig. 1. Transmission electron microscopy image of HSA NPS 
The composites, obtained by complexation of HSA and HSA NPs with chlorin e6, were characterized by UV-Vis spectrometry and fluorescence analysis. Fig. 2 shows absorption spectra of chlorin e6 and its composites with HSA and HSA NPs, cross-linked by 20 and $100 \%$, respectively. It can be seen that complexation of the PS with HSA and especially with its NPs induces increase of PS red absorption maxima and slight bathochromic shift of spectral $B$ bands.

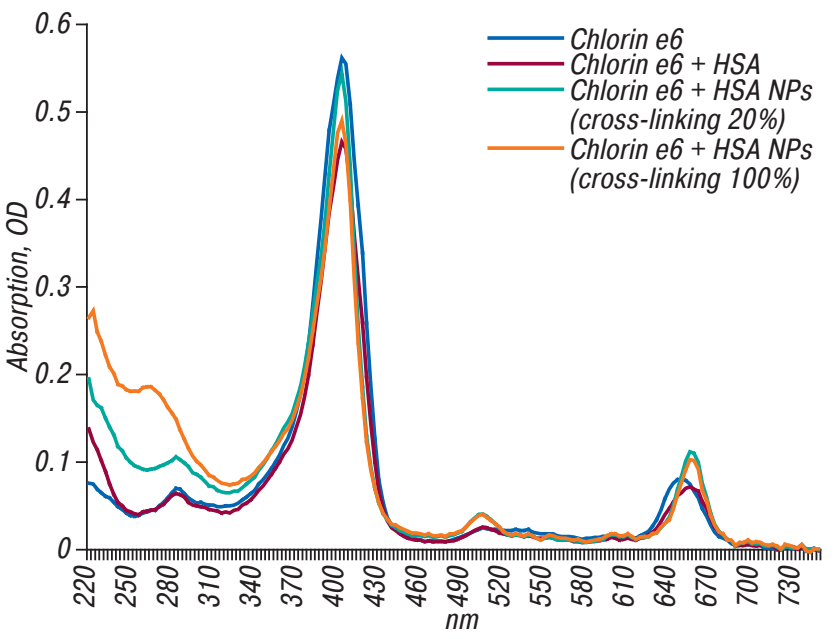

Fig. 2. Absorption spectra of HSA and HSA NPs composites with chlorin e6. Protein to PS w:w ratio is $1: 1$

Fluorescence spectroscopy (Fig. 3) also demonstrated the distinct shift of chlorin e6 $662 \mathrm{~nm}$ band to longer wavelengths under complexation with albumin preparations, and an augmentation of the tendency is evident when HSA NPs were used instead of initial albumin. The changes observed may be presumably explained by appearance of new binding sites in cross-linked protein molecules as it was showed in some previous studies [13].

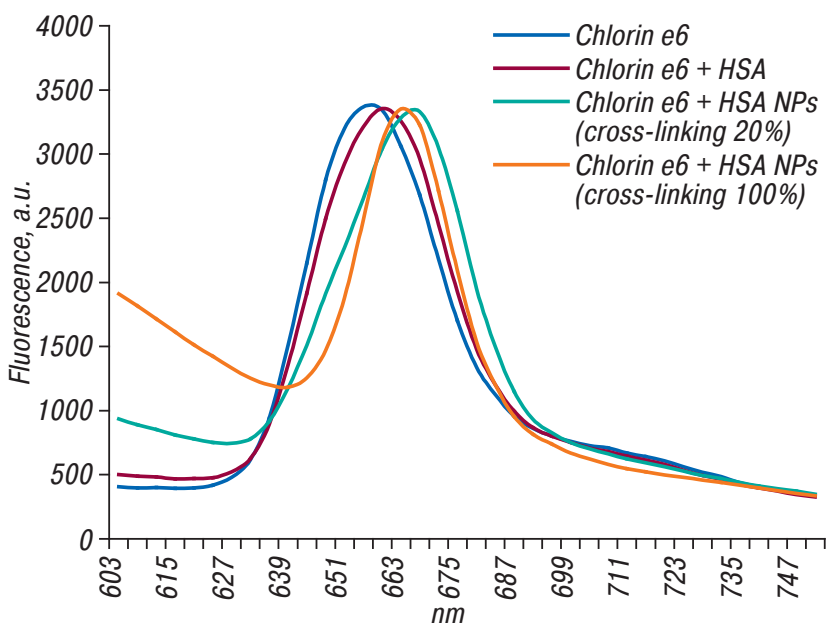

Fig. 3. Fluorescence spectra of chlorin e 6 composites with HSA and HSA NPs. Protein to PS w:w ratio is $1: 1$

HSA NPs cytotoxicity and cell interaction. Dark cytotoxicity study (without photoirradiation) of the HSA-NPs with different aminoacid residues crosslinking degree $(20 ; 40$, and $100 \%)$ was conducted in parallel on MT-4 malignant cell line and on normal human lymphocytes. It showed an absence of HSANPs negative effects on cell viability (data not shown) up to the concentration of $1 \mathrm{mg} / \mathrm{ml}$, that was 5 times higher than a maximal dose, used in further research.
To analyse HSA NPs interaction with malignant cells, the NPs (100\% cross-linking) were conjugated to FITC, and the conjugate was used for MT-4 cells treatment. Fluorescence microscopy of the conjugatetreated cells revealed that HSA-NPs are significantly superior than initial albumin molecules adsorbed on the surface of malignant lymphocytes (Fig. 4). The accumulation of NPs was time- and concentrationdependent with the maximum reached after 4 hours of cell incubation with $300 \mu \mathrm{g} / \mathrm{ml}$ NPs. Nevertheless, aliready in $30 \mathrm{~min}$ of incubation the difference between the accumulation of HSA and HSA-NPs on cells was clearly visible.

Thus, comparative analysis of accumulation kinetics of FITC-labeled purified albumin and its nanospheres by MT4 cells demonstrated high affinity of the NPs to malignant cell membrane.

Photodynamic activity of HSA NPs composites with chlorin e6. Photodynamic activity of nanocomposites chlorin e6-HSA NPs with different degree of albumin cross-linking was studied in experiments in vitro on malignant lymphoid cell line MT-4 and normal lymphocytes isolated from the healthy donor blood. The data presented in Fig. 5, a, evidence that photodynamic efficiency of nanocomposites elevated along with increasing percentage of cross-linked amino acid residues in HSA NPs. The photodynamic damage of MT-4 cells preincubated with chlorin e6-HSA NPs (100\%) was up to $20 \%$ higher than in tests with the free chlorin e6. At the same time the initial HSA significantly reduced photodynamic effects of chlorin e6. It is important to note that in experiments with normal human lymphocytes, unlike malignant lymphoid cells, HSA NPs (100\%) also reduced the chlorin e6 photodynamic activity (Fig. $5, b$ ).

Chlorin e6-HSA NPs circulation in the blood of mice. Since in vivo PDT studies with chlorin e6-HSA NPs as a PS are planned, the investigation of the nanocomposite elimination from the blood was undertaken. The solutions of chlorin e 6 and its HSA NPs composite with equal content of chlorin e6 were injected into the tail vein of $\mathrm{C} 57 \mathrm{BI} / 6$ mice. The chlorin e 6 fluorescence $\left(\lambda_{\text {emission }}=670 \mathrm{~nm}\right)$ in the blood samples was estimated during $24 \mathrm{~h}$ by fluorimetry.

As it can be seen from Fig. 6, in 15 min after the nanocomposite chlorin e6-HSA NPs introduction to animals about $30 \%$ more of it was detected in the bloodstream in comparison with the free PS introduction. In one hour, the difference was still 27\%. But three hours after the experiment beginning, plasma fluorescence intensity decreased by 10 times, and the difference between the animal groups was practically imperceptible. Alter $24 \mathrm{~h}, \mathrm{PS}$ fluorescence in the blood plasma was no longer detectable. Thus, it can be concluded that chlorin e6 complexation with HSA NPs is capable to prolong the PS blood circulation.

The principal idea of the present study was to synthesize and to test a composite of chlorin e6 with albumin nanoparticles which could serve not only as PS transporters but also to protect it from protein 


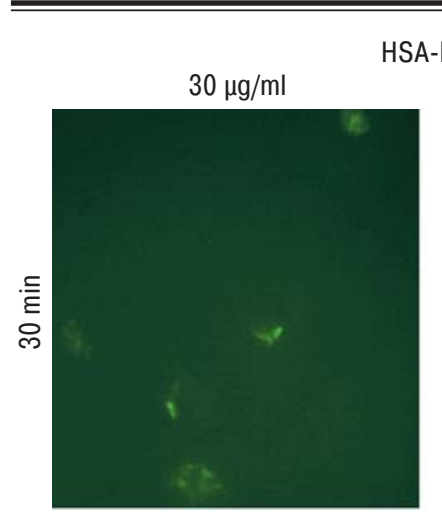

HSA-FITC
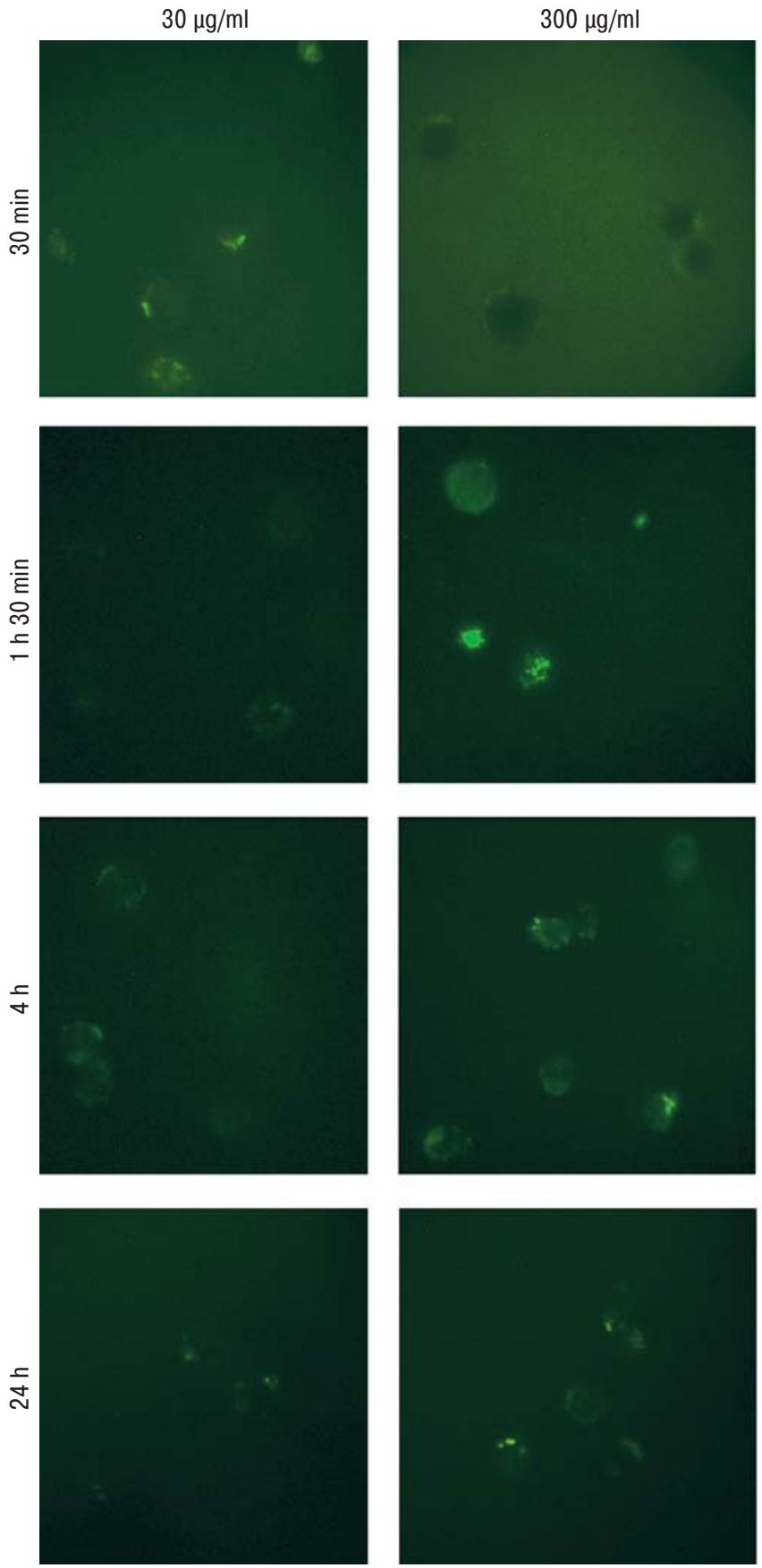
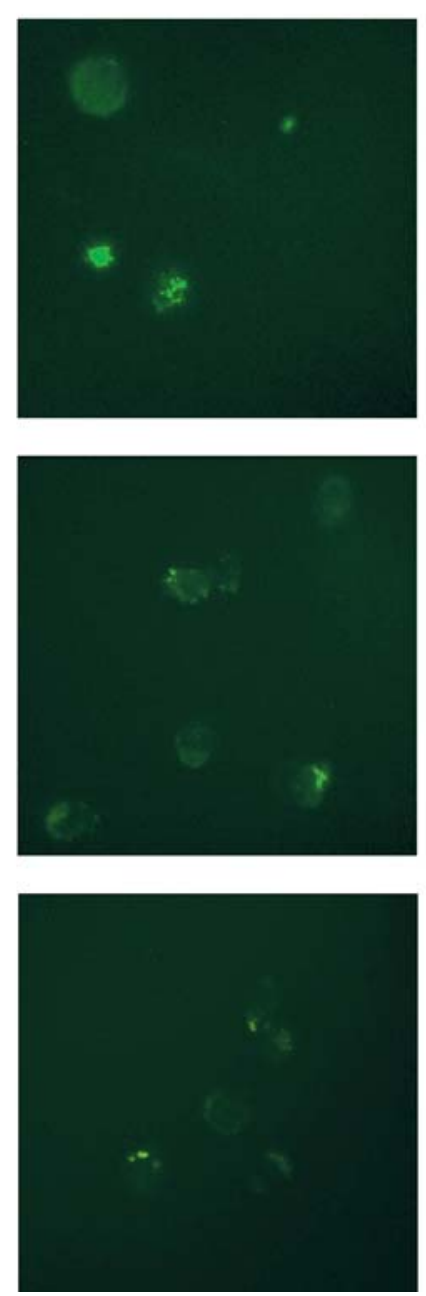

HSA-NPS-FITC
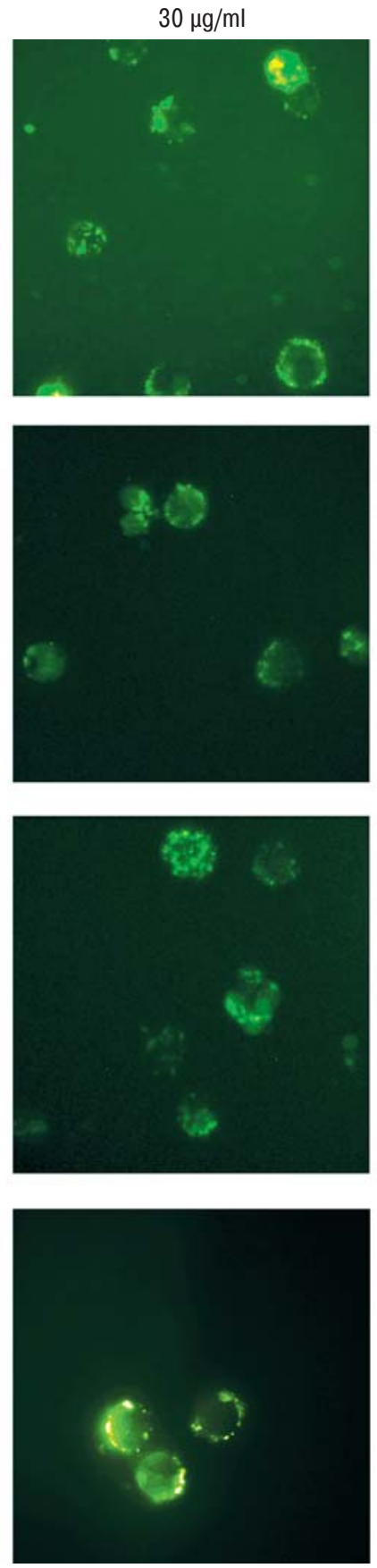

$300 \mu \mathrm{g} / \mathrm{ml}$
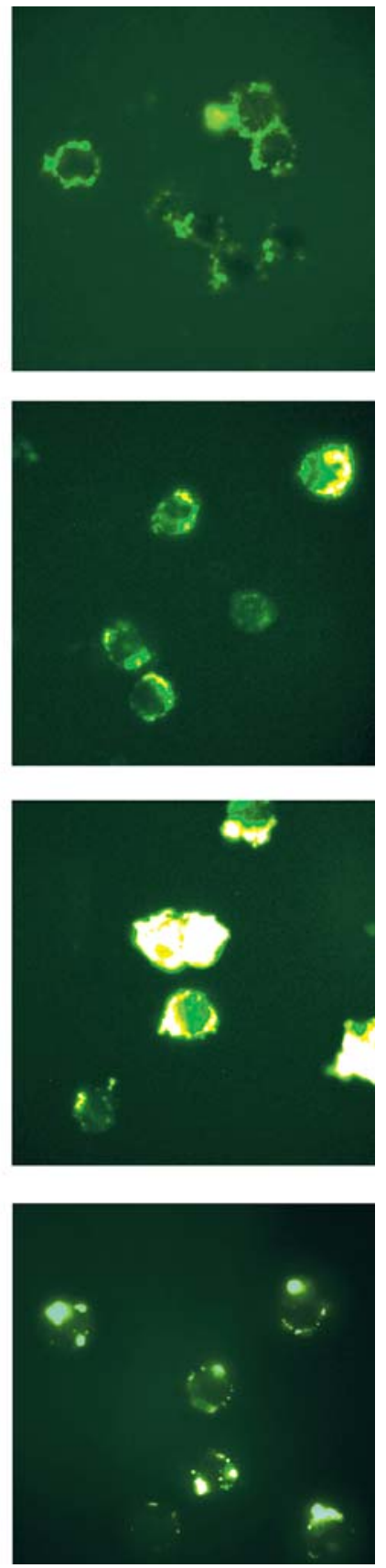

Fig. 4. Kinetics of FITC-labeled HSA and HSA-NPs accumulation on the MT-4 cell surface (magnification, $\times 400$ )

corona formation in biological environment and from fast removal from the blood by the reticuloendothelial system. The current strategy of controlled drug delivery involves the use of serum albumin as one of the main carriers for pharmaceutical preparations [17-19]. This protein is highly resistant to a wide range of environmental $\mathrm{pH}$ (4 to 8 ), thermally stable (up to $60{ }^{\circ} \mathrm{C}$ ), biodegradable, has low toxicity, low immunogenicity, relatively long half-life (19 days), and high affinity to tumor cells and inflamed tissues. Additionally, the albumin has a unique three-domain structure represented by multiple active binding sites [20].

Nanoparticles of natural materials such as albumin are actively tested not only for transport of therapeutic molecules, but also proteins, DNA and oligonucleotides. Abraxane - drug consisting of albumin with paclitaxel on its surface, is already introduced in clinical practice to treat breast cancer [21, 22]. Albumin conjugate with methotrexate (MTX-HSA) is also at the stage of clinical trials for kidney cancer therapy. HSA-NPs are actively tested as transporters for PSs such as pheophorbide [9], chlorin e6 [23], meta-tetra(hydroxyphenyl)chlorin and meso-tetra(hydroxyphenyl)porphyrin [12], and NPs from bovine serum albumin - for phthalocyanine derivative [24].

The chlorin e6-HSA NPs composite described in the present study is only slightly superior to the free chlorin e6 by its in vitro photodynamic activity and blood-circulation kinetics. However, the results of full-fledged PDT experiments in vivo will allow finally evaluate the potential of this nanocomposite PS. 

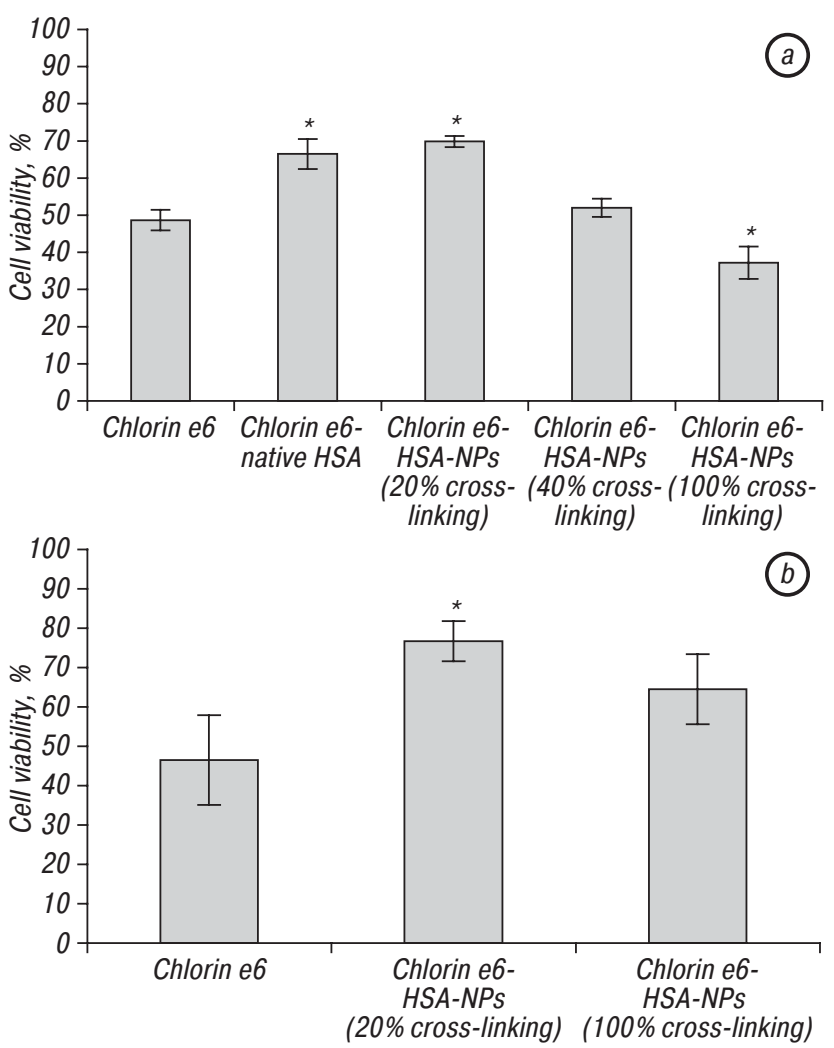

Fig. 5. Photodynamic activity of chlorin e 6 composites with HSA and HSA NPs containing different percentage of cross-linked amino acids: $a$ - MT-4 malignant lymphocytes, $b$ - lymphocytes of healthy donors. Each point represents the means \pm SD of triplicate samples. ${ }^{*} p<0.05$ chlorin e6 vs. chlorin e6-HSA NP

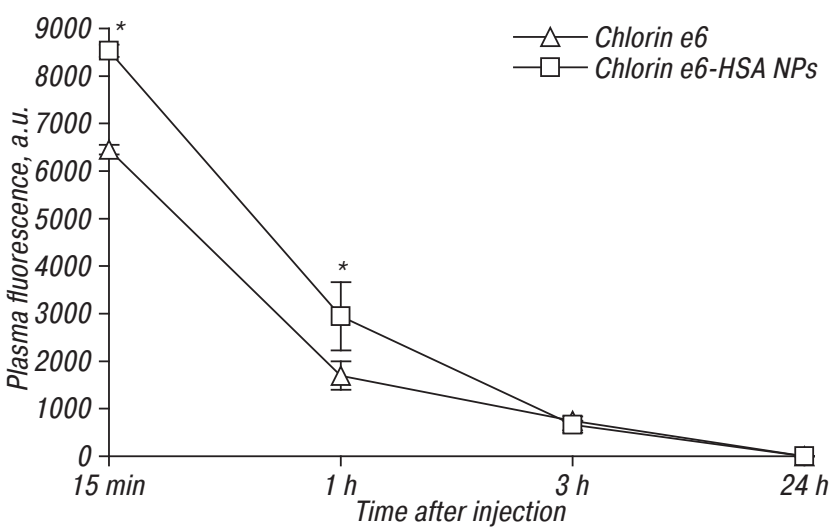

Fig. 6. Nanocomposite PS elimination from the blood of mice. Each point represents the means \pm SD of triplicate samples. ${ }^{*} \mathrm{p}<0.05$ chlorin e6 vs. chlorin e6-HSA NPs

\section{ACKNOWLEDGEMENTS}

The work of N.F. Gamaleia and I.O. Shton was supported in part by the NATO SPS Programme Multi-Year Project No. 984702.

\section{REFERENCES}

1. Bechet $D$, Couleaud $P$, Frochot $C$, et al. Nanoparticles as vehicles for delivery of photodynamic therapy agents. Trends Biotechnol 2008; 26: 612-21.

2. Gamaleia NF, Shton IO. Gold mining for PDT: Great expectations from tiny nanoparticles. Photodiagnosis Photodyn Ther 2015; 12: 221-31.

3. Saboktakin MR, Tabatabaee RM. The novel polymeric systems for photodynamic therapy technique. Int J Biol Macromol 2014; 65: 398-414.
4. Li L, Huh KM. Polymeric nanocarrier systems for photodynamic therapy. Biomater Res 2014; 18: 19.

5. Chen B, Pogue BW, Hoopes PJ, Hasan T. Vascular and cellular targeting for photodynamic therapy. Crit Rev Eukaryot Gene Expr 2006; 16: 279-306.

6. Kessel D, Thompson P, Saatio K, Nantwi KD. Tumor localization and photosensitization by sulfonated derivatives of tetraphenylporphine. Photochem Photobiol 1987; 45: 787-90.

7. Frei E. Albumin binding ligands and albumin conjugate uptake by cancer cells. Diabetol Metab Syndr 2011; 3: 11 .

8. Kramer PA. Letter: Albumin microspheres as vehicles for achieving specificity in drug delivery. J Pharm Sci 1974; 63: $1646-7$.

9. Chen K, Preuss A, Hackbarth S, et al. Novel photosensitizer-protein nanoparticles for photodynamic therapy: photophysical characterization and in vitro investigations. J Photochem Photobiol B 2009; 96: 66-74.

10. Chen K, Wacker M, Hackbarth S, et al. Photophysical evaluation of mTHPC-loaded HSA nanoparticles as novel PDT delivery systems. J Photochem Photobiol B 2010; 101: 340-7.

11. Wacker M, Chen K, Preuss A, et al. Photosensitizer loaded HSA nanoparticles. I: Preparation and photophysical properties. Int J Pharm 2010; 393: 253-62.

12. Preuss A, Chen K, Hackbarth S, et al. Photosensitizer loaded HSA nanoparticles II: in vitro investigations. Int J Pharm 2011; 404: 308-16.

13. Weber C, Coester C, Kreuter J, Langer K. Desolvation process and surface characterisation of protein nanoparticles. Int J Pharm 2000; 194: 91-102.

14. Sarnatskaya VV, Lindup WE, Walther $P$, et al. Albumin, bilirubin, and activated carbon: new edges of an old triangle. Artif Cells Blood Substit Immobil Biotechnol 2002; 30: 113-26.

15. Sarnatskaya VV, Lindup WE, Ivanov AI, et al. Extraction of uraemic toxins with activated carbon restores the functional properties of albumin. Nephron Physiol 2003; 95: 10-8.

16. Nitta SK, Numata K. Biopolymer-based nanoparticles for drug/gene delivery and tissue engineering. Int $\mathbf{J}$ Mol Sci 2013; 14: 1629-54.

17. Kratz F. Albumin as a drug carrier: design of prodrugs, drug conjugates and nanoparticles. J Control Release 2008; 132: $171-83$.

18. Taheri A, Atyabi F, Salman Nouri F, et al. Nanoparticles of conjugated methotrexate-human serum albumin: preparation and cytotoxicity evaluations. J Nanomater 2011; 2011: 1-7.

19. Fanciullino R, Ciccolini J, Milano G. Challenges, expectations and limits for nanoparticles-based therapeutics in cancer: a focus on nano-albumin-bound drugs. Crit Rev Oncol Hematol 2013; 88: 504-13.

20. Otagiri M, Kragh-Hansen U, Imai T. Albumins with new functions and clinical applications. Drug Metab Pharmacokinet 2009; 24: 285-6.

21. Cho K, Wang X, Nie S, et al. Therapeutic nanoparticles for drug delivery in cancer. Clin Cancer Res 2008; 14: 1310-6.

22. Gradishar WJ, Tjulandin S, Davidson $\mathrm{N}$, et al. Phase III trial of nanoparticle albumin-bound paclitaxel compared with polyethylated castor oil-based paclitaxel in women with breast cancer. J Clin Oncol 2005; 23: 794-803.

23. Jeong $\mathrm{H}$, Huh M, Lee SJ, et al. Photosensitizerconjugated human serum albumin nanoparticles for effective photodynamic therapy. Theranostics 2011; 1: 230-9.

24. Portilho FA, Cavalcanti CEO, Miranda-Vilela AL, et al. Antitumor activity of photodynamic therapy performed with nanospheres containing zinc-phthalocyanine. J Nanobiotechnology 2013; 11: 41-55. 